\title{
Use of Debris Program of Civil Construction Waste Management in Containment Residential Erosion Geovanni Braga in Anapolis in the State of Goiás
}

\author{
Welvis Furtado da Silva ${ }^{1}$, Ernane Rosa Martins ${ }^{2}$ \\ ${ }^{1}$ Department of Environmental Engineering, Metropolitan Institute of Education and Culture, Anápolis, Brazil \\ ${ }^{2}$ Coordination of Information Technology Area, Federal Institute of Education Science and Technology Goiás, Luziânia, Brazil
}

\section{Email address:}

welvisfurtado@anapolis.go.gov.br (W. F. da Silva), ernane.martins@ifg.edu.br (E. R. Martins)

\section{To cite this article:}

Welvis Furtado da Silva, Ernane Rosa Martins. Use of Debris Program of Civil Construction Waste Management in Containment Residential Erosion Geovanni Braga in Anapolis in the State of Goiás. American Journal of Civil Engineering. Vol. 3, No. 6, 2015 , pp. $207-216$. doi: 10.11648/j.ajce.20150306.12

\begin{abstract}
The gullies can cause great damage to the environment and also the very human environment, as one of the main consequences of this erosion is the major loss of soil mass. This work aims to present the use of debris originating from demolition in construction to contain the degraded area that causes environmental impact at Residential Geovanni Braga by the Municipal Works, Urban Services and Property Annapolis City Hall in the State of Goiás in the year of 2015. The methodology of the proposed study is theoretical, / literature, practical / field work / case study and qualitative and quantitative descriptive. Adopted the use of discarded materials such as: debris of construction material, tires, wood and shackles for sewage or storm water. As a result it was found that the techniques used in the treatment of erosion was rapid, extremely efficient and extremely cost-effective when compared to traditional methods, pleasing the residents' association and improving the aesthetics of the place before degraded.
\end{abstract}

Keywords: Construction Waste Destination, Erosion Containment, Degraded Areas, Environmental Impact

\section{Introduction}

Erosion is a ground displacement process or rocks from a surface. Erosion can occur per share of natural phenomena or human. With regard to acts of nature, we can mention the rains as the major agent of erosion. Upon reaching the ground, in large quantities, causing landslides, seepage and changes in terrain consistency. Thus, it causes the earth displacement. The wind and temperature change are also important cause erosion.

The implementation of vegetables in areas with natural kicking erosion is to minimize or eliminate the adverse effects of interventions and environmental changes inherent to drag the soil at a particular location.

In urban areas these spaces have the potential to function as temperature amenizadores (climate control), lower noise and carbon dioxide levels (improving air quality) promote the medium disorders balance (protection against floods and droughts) protect watersheds to supply clean water (control and water supply), provide shelter for wildlife (fauna and biological control of refuge) and contribute to the aesthetic improvement of the landscape.

To work around this urban problem, the development of normative solutions and appropriate works projects to each situation is needed. These solutions should be simple and less costly but efficient and to justify public investment, resulting in security for the population and for public facilities in order to return the area to its urban use.

Thus, this research aims to present the use of debris Construction in curbing the environmental impact of erosion Residential Geovanni Braga by the Municipal Works, Urban Services and Property Annapolis City Hall in the State of Goiás in 2015.

The methodology of the proposed study is theoretical, / literature, practical / field work / case study and qualitative and quantitative descriptive.

It adopted the use of discarded materials such as: urban cleaning debris, construction material, tires, wood and shackles for sewage or storm water.

This research is justified by the limited literature on the use of rubble from civil construction and / or street cleaning in curbing the environmental impact of erosion. 
So based on the above, this article is divided into five sections, in this present section presents besides the introduction, the definition of the research problem, the goal, the rationale and importance of the study and structure of this research. Section two (02) brings the theoretical framework, with the formation of a conceptual and theoretical base, providing subsidies for the development of this study. In section three (03) presents the method used and the technical and methodological procedures used for the study. In section four (04) presents the analysis and discussion of the results obtained in the research. Finally, in section five (05) conclusions are drawn.

\section{Literature Review}

The environmental protection has been instrumental for establishing and maintaining urban developments, industrial, agricultural, commercial and road, under the legislation and also for the surveillance of society thus avoiding degradation and environmental destruction. The Brazil, a tropical country with strong intemperate conditions such as heat stroke and heavy rains have contributed to accelerate the erosive processes that normally there is no preventive treatment, but in some cases only the concealer, bringing recovery of costs [1].

The removal of vegetation from an area leaves it exposed to erosion caused by falling water droplets, mainly from rainfall, which ends up resulting in a mass movement in the soil. "The process responsible for the breakdown of the soil, after removal of the vegetal layer on its surface, is the impact of rain water droplets, thus the pellets are transported from one location to another" [2].

After a long rainy season, these water impacts with the ground end up generating a stream of sediments that can lead ravines, and if the process is continued cause incessant deepening of the soil, being able to reach the level of a gully.

The gullies are the most advanced stage of erosion and thus more difficult to contain. Are products of surface waters, running on the surface, causing wear, landslides, soil hauls etc., can also be caused by deep waters, infiltrating the ground, walk through into the profile, more or less vertically, to find a impermeable or less permeable layer where they accumulate and moving horizontally, causing mudslides and landslides [3].

Erosion and other factors is caused by a group of geodynamic processes, driven by energy and gravitational potential energy associated with the uneven terrain [4].

Ferreira et al. (2007), states that "the gullies are considered one of the worst environmental problems in areas of crystalline rocks in mountainous tropical regions where they are frequent and can reach large" [5].

To Ab'Saber (1968), the process of formation of gullies is associated to landscapes from which it was withdrawn their vegetation. In these landscapes, water runoff to linearly move through the soil and reach the water table, compromises the stability of the area and lead to the formation of gullies [6].

According to Lima (2003), soil erosion affects life in many ways, there is an issue that involves professionals from various fields of knowledge, sometimes with different views on the same issue. There are lines of research on erosion nationwide in agronomy, geography, geology, geotechnical and other areas of knowledge [7].

According Iwasa \& Fendrich (1998), most municipalities is affected by linear erosion, mainly caused by the concentration of water runoff [8].

The great detonator of urban erosion is concentrated runoff on impermeable areas with weak or non-existent drainage system.

Camapum de Carvalho et al. (2006) point out that, in engineering works such as dams, transmission and road lines, the inappropriate release of water and the loan abandonment of areas explored without adequate technical care may also be related to the genesis of erosion [9].

Landslides are fast-moving, large amounts of material, which typically occur as a result of the existence of discontinuity in the soil profile, imperfect geotechnical works (embankments) and the very dynamic areas with rugged terrain. Are also considered within the scope of erosion, although they are usually neglected in the context of soil erosion study, which can also lead to the formation of gullies [10].

According to Embrapa soils (2002), the correction voçorocamento areas can be made in order to "control erosion in the area upstream or the slope bedside, retention of sediments inside the gully, reforestation of catchment areas (bedside) and inside the gully with plant species that are able to develop properly in these locations." [11].

Many are the costs involved for the recovery of degraded areas by gullies, such as hand labor used, inputs, cost of seedlings and transport of the same, etc. The cost of recovering such an area will depend mainly on the size (length, width and depth) of the gully one wants to retrieve, thereby evaluating whether an intervention is economically viable in voçorocada area.

In this context, this study aimed to demonstrate the areas recovery method eroded using rubble and see if the technique used to stem the erosion is valid or if there are flaws that can be corrected.

It is understood by the rubble fragments together from the waste in the construction, renovation and demolition of several buildings structures such as buildings, houses and bridges.

Among the projects that used rubble and succeeded in erosions of contention are:

The project carried out by Carvalho (2004), which was used from the rubble generated in the city to contain about 10 gullies as the rehabilitation of the Villa St. Matthew, in the neighborhood Estrela Dalva in Contagem (MG), which was transformed into terrace (flat area) for disposal of inert waste (debris) and will eventually be deployed a linear park with funds from the Brazilian Institute of Environment and Renewable Natural Resources (IBAMA). In addition to this, the same method was used in Piraquara neighborhood near the center of the city, and the region of Wholesale Markets (CEASA) [12].

Cappi (2004) also conducted an environmental recovery work of eroded areas as the destination alternate ending of scrap tires. According to him, this technology presents operating low cost characteristics and the advantage of 
providing indirect control the dengue mosquito, and recover degraded areas by large erosion (gullies) or build them siltation barriers as part of the landscape recovery strategy eroded, which will then be revegetated. For this, we used two different techniques: the construction of embankments to sediment through tire barrier and complete burial of tires in the gully bottom. The second technique used more tires and the restoration of landscape after the end was faster [13].

It is known that the construction industry is the major generator of rubble and it is known, too, that this practice is inevitable. However, one can adopt efficient measures that do not degrade the environment and, in turn, will bring some social benefit.

It is also known that the use of whole tires associated with large plant roots can be used to assist in the containment of soil erosion [14]. As the filling of landfill using shredded tires to replace part or whole of aggregate with low cost and keep the soil with good drainage [15].

Another technique that can be used is composting, which is the aerobic decomposition process of organic matter under appropriate conditions, which aims to turn the waste into a product of good quality, which has several benefits for agricultural products besides being a good soil conditioner because of its physical characteristics, chemical and biological.

The composting technique is shown to be of utmost importance to reduce the environmental damage caused by the improper disposal of organic waste. Therefore, the compost should be seen as an environmental biotechnology, as the benefits of your choice as a key strategy to make up the management of organic waste, whether in urban or rural setting, or generators as agro-industrial or industrial complex, constitute the process enabling compliance with the items considered fundamental the concept of sustainable development for the efficient treatment and disposal of solid waste. With the minimization of environmental impacts, minimizing waste and maximizing recycling.

Haug (1993) means that this process (composting) occurs on conditions allowing high temperatures, and a result of the aerobic biological decomposition of organic substrates, achieving a stable end-product for storing and applying to the soil, further highlighting the lack of environmental effects Undesirable [16].

Note also, that composting is essential for sustainable development, and that literature poses many benefits from composting technology, "compound (...) is a valuable soil conditioner, source of humic substances, and range of nutrients that provide growth of plants in horticulture, gardening and horticulture" [17].

Thus, bioengineering is a combination of alternatives involving biodegradable structures such as vegetable fibers, live cuttings, timber and rigid structures such as stone, concrete, iron, among others.

According to Gray and Sotir (1995), all erosion has a negative visual appearance showing signs of neglect, danger and environmental degradation, and most often silted sediment to waterways, contributing to assoreá them and washing / removing the layer fertile soil [18].
According to Goldman (1986) almost all erosion is possible to control and recovery, so the techniques used here will be useful in the control of existing erosion [19].

\section{Research Methodology}

The methodology of work is theoretical / bibliographic nature, practical / field work / case study and qualitative and quantitative descriptive.

To carry out this study a literature review was performed, since this theme recurs in several studies conducted in various regions of Brazil.

They used photos and satellite images, to study the area and understanding of the problems caused by erosion.

This study is characterized as descriptive of the nature of the objective, as it has in order to describe the characteristics involved in the project undertaken [20].

The case study was chosen because it is a study of empirical investigating a particular phenomenon, contemporary, within a real life context, in the case of an in-depth analysis of an object (case), allowing its broad and detailed knowledge [21]. Its aim is to deepen the knowledge about a problem not sufficiently defined [22] to stimulate the understanding, suggest hypotheses and questions or simply develop the theory. This attempts to explain why a decision or set of decisions were taken, how they were implemented and what results have been achieved [23].

We opted for the recovery of degraded areas by reusing discarded materials, such as debris materials from construction and urban cleaning, tires, wood and shackles for sewage or storm water, in order to decrease public investments Since the spoils were donated by gathering companies such materials of construction of the city.

We used field research to collect data through semi-structured questionnaire to identify the level of satisfaction of the neighboring population to work, comprising an objective question (approve or not approve) and four essay questions, whose answers were recorded by the researcher and later transcribed.

Respondents were invited to participate in visit "in loco", being chosen the residents of the neighborhood where it is located erosion. It stipulated a distance of 200 meters from any axis thereof to denote the sharp contours.

The method of analysis used data primarily consisted of using Microsoft Excel 2013® program, where he designed a database that has been fed with those obtained questionnaires. Then there was the descriptive analysis of the answers given by local residents.

It was used content analysis to analyze strategy of research data.

\section{Analysis and Discussion of the Results}

\subsection{Presentation Area}

The gully Geovane Braga is located in the eponymous district and is bordered upstream by Street May 13 and its left 
bank by the Ombudsman Street and 4th Street, at coordinates 717928 E / 8189088 N. This process voçorocamento settled perpendicular to the slope Goes Stream, a tributary of the Antas River, as shown in Figure 1 Goggle Earth date of $05 / 31 / 2015$.

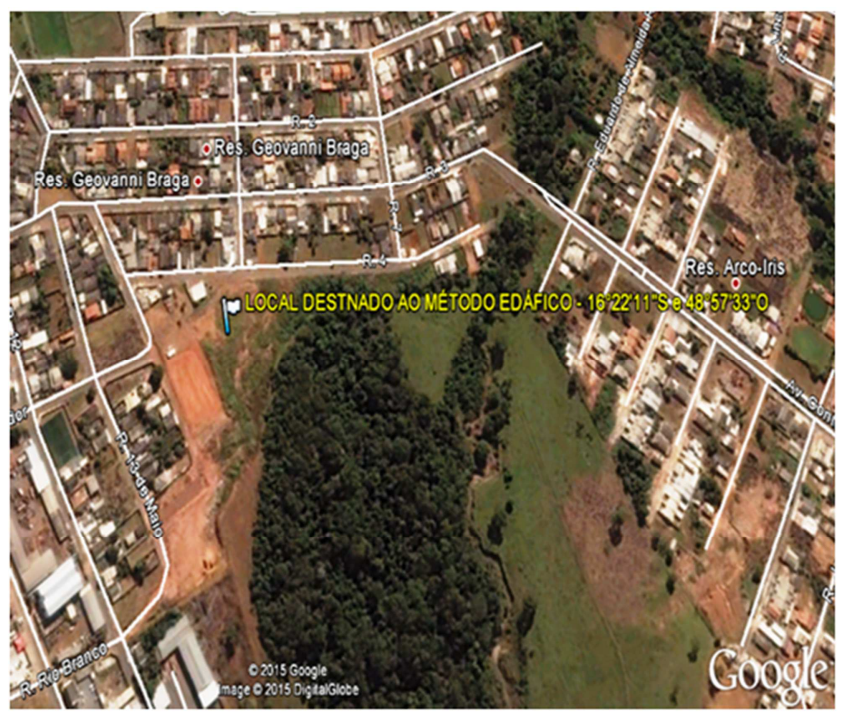

Figure 1. Local intended to edáfico Method.

The erosion was arranged in the direction North West / East, it has a linear shape with a length of approximately 550 meters, the average width of approximately 25 meters and an average depth of approximately 12 meters.

Its banks were still expanding, because of the development of the mass movements of the type slipping and his head had large amount of landfill with debris and trash.

The head of the gully position of a concave side, the upstream soil sealing and inefficient drainage system and extensive street in the slope favored the concentration of runoff flow this hillside contributing to the erosion. In addition, the release of water from the rainwater catchment system the hillside was highlighted as the triggering of voçorocamento.

During the conducted field survey it was found that part of the vegetation of the area in natural kicking erosion, especially on hilly region of the right bank of the above address was virtually wiped out by man-made phenomena and the nature of that soil range for several years, without steps were taken to recover said area. However held civil engineering works in the vicinity thereof to contain the problem of excess runoff and disposal of municipal waste, but reflections of the latter offense can still be seen at the site due to the insistence of some community members to discard various waste in the area.

\subsection{Area Characterization}

According to Nimer (1989), the dominant climate in the savannah region is humid subtropical warm type characterized by two distinct seasons, a drought that matches the autumn-winter period, and another humid with heavy rains corresponding to the period of spring-summer, where $70 \%$ of the total accumulated rainfall during the year is concentrated between November to March, usually the wettest quarter from January to March, when it rains on average $45-55 \%$ of the annual total [24].

Though quite antropisada, the area under review presents an excellent kicker processes in the erosion problem and disposal of municipal solid waste that were frequently on site.

The area occurs in topography in sharp gap not being semi flat whose adjacent drainages belonging to the Rio das Antas basin.

From the point of view of geology, the city of Anapolis is in the field of Goiás complex, existing rocks of the granulite complex (Archean), the Araxá Group (Mesoproterozoic) Detritus and-lateritic cover (tertiary and quaternary). In the southwest portion predominance of lateritic yoke in relief flattened and granulites the dissected areas.

The main feature lies in the dominance of deciduous species such as red mimosa (governed Parapiptadenia), mastic (Astronium SP), yellowing or garapa (Apuleia praecox) and others.

In general the massive degradation is more relevant on the surfaces receiving the afternoon sun and / or those who receive the sun all day, because this is a big temperature difference between day and night. This gradient promotes drying of the soil which in turn tends to increase the pressure in the air inducing phase greatest amount of contraction cracks which can be reflected inside the mass unsettling it and favoring the erosive process.

The gully Geovane Braga evolved in the shed on the left bank of the stream Goes, a tributary of the Antas River. The highest peaks are in the watershed tops and smaller close to the watercourses. Since the tops predominate altimetry diversity of Medium / Low to Medium that are accentuated on time in erosive edges of the tops Plans west and east dissecting modeled where stands altimetry diversity predominantly Alta. The High altimetry diversity of sites also have high slopes of 10 to over $45 \%$. The topographic description allows watching even the inclination of the slope steepness marked by greater than $45 \%$. On the left bank of the gully prevailing slopes ranging from 5 to $10 \%$ and on the right bank predominant slopes between 15 and 30\%. Low $2 \%$ lower slopes outline the flattened tops. Immediately upstream of the gully it can check the presence of timely Concave-concave relief transitioning to aspects predominantly Rectilinear-Rectilinear and later Concave-convex to the head of the gully become convex-concave and later Concave-convex, the latter being very concentrators Flows [25].

With regard to the orientation of the slopes west bank of the watershed is predominantly oriented to the west and northwest. On the east bank of the watershed where processes have a direct relationship to the gully described in this item predominate slopes oriented to the east, but the closest banks of the gully have a different orientation, with the left-oriented bank the South and the right to North. Then the right edge gets higher solar radiation, and this interaction soil / atmosphere may be observed in the field, since the 
slope of that edge presents less humid than the other side. Evolutionarily, the right bank that receives more sunlight tends to evolve laterally more sharply [25].

Moreover, it is observed that this enlargement diminishes the sharp edge is present in the portions where the slope is flanked by a fragment gallery forest. In this, the vegetation may be acting as a mitigating action of solar radiation. As for drainage away from the Modeled grooming remains distant 100-1000 meters from from water courses while on patterned dista dissecting 0-100 meters, and the interception of the water table caused by the great depth of the incision [25].

\subsection{Recovery Procedure}

The recovery of the area was carried out by edáfico method, which includes the recovery of all battered area in the primitive land containing approximately $8214 \mathrm{~m}^{2}$, the more the soil profile (slope) on the edge of the forest, as shown in Figure 2.

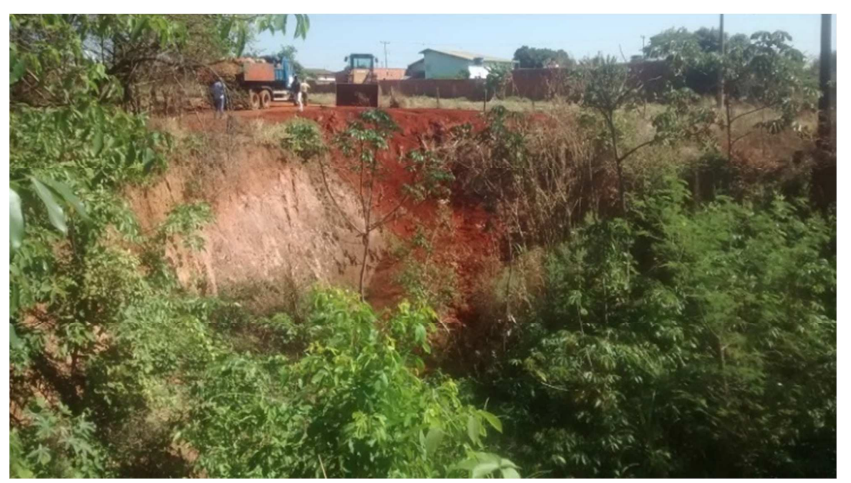

Figure 2. Erosion.

The following describes the techniques and methods used in operating result in the stabilization and control of erosion.

\subsubsection{Removal of Loose Sediment Segregation of Waste}

This operation consists of removing all loose sediment and also those who were in unstable conditions. The removal was done manually and with the use of machines as shown in Figure 3.

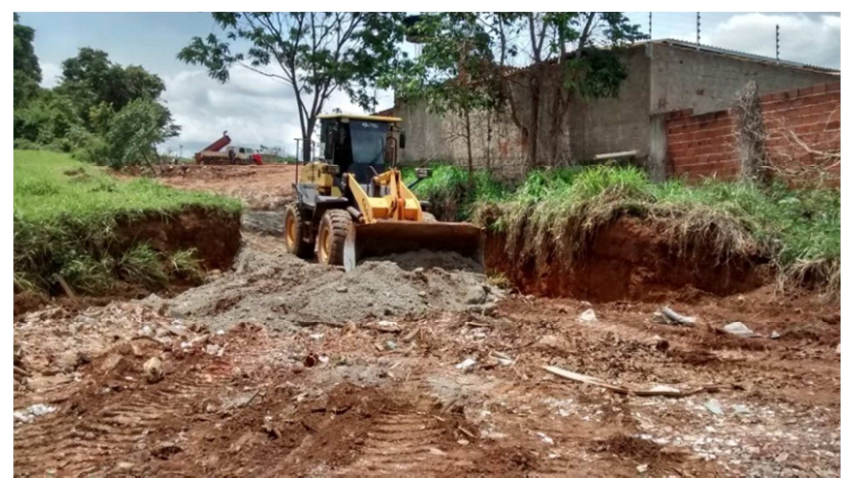

Figure 3. Use of machinery.

It was allowed to waste pickers perform the collection, as shown in Figure 4.

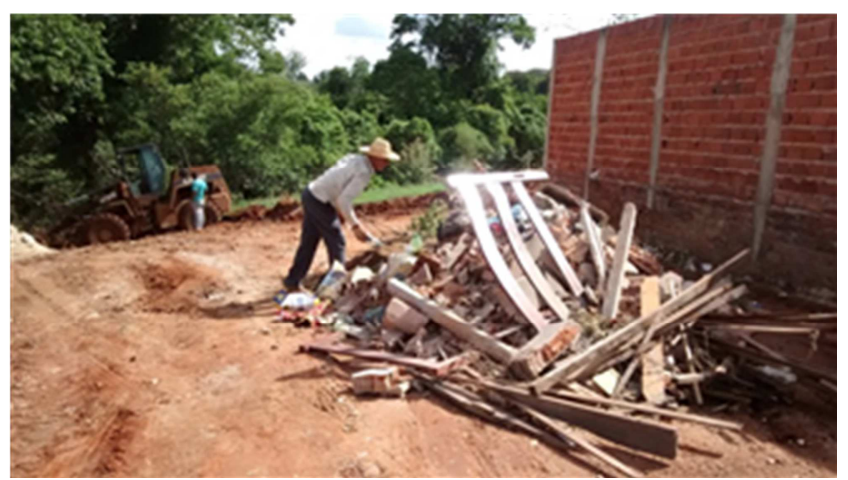

Figure 4. Waste Segregation manually.

The local government allowed the population had free access to the site, however, was allowed only the disposal of rubble. Companies (disk-rubble) responsible for collecting this type of material were asked to sift through and gather their buckets, any other kind of material between them, such as soda cans, water bottles, candy wrappers and ice cream, as shown in Figure 5.

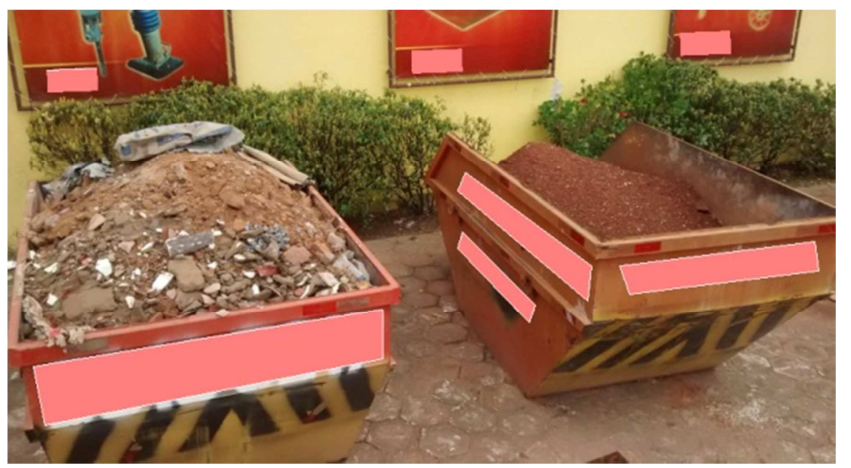

Figure 5. Buckets with segregated rubbish.

The method used by the city is second to no other known.

\subsubsection{Protection of the Headwaters of Erosions}

The protection of headwater erosion was made with the construction of drainage channels and protective barriers, in order to reduce the speed of water that could cause erosion causing all the work performed was damaged.

Channels are designed so as to meet local needs, due to rainfall.

\subsubsection{Anchoring Sediments}

The first rains could compromise the work if the sediments were not anchored. These sediments should be retained until the vegetation is established.

The anchoring sediment was performed with the use of wood palisades.

This method was chosen because it proved adequate to prevent failure in the work and cost reduction.

The construction of the palisades was taken downstream of the gully with sewage or rainwater shackles no longer usable available in town, as shown in Figure 6. 


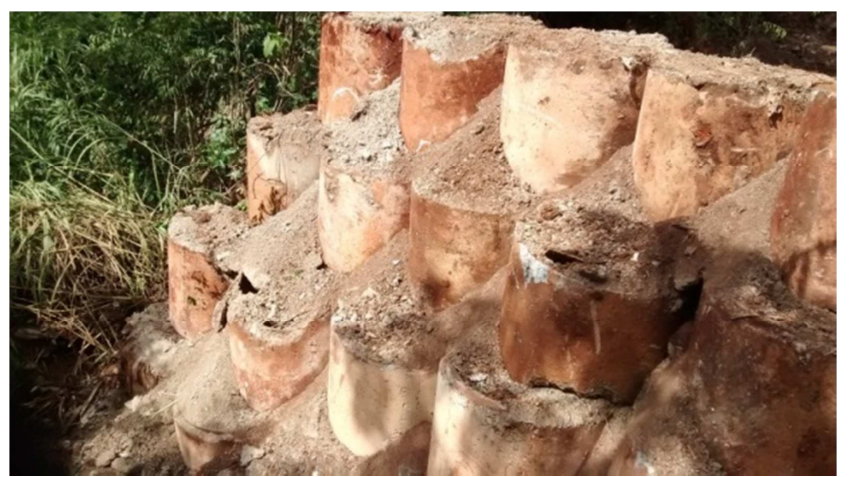

Figure 6. Anchoring.

To fix the palisades were held drainage lines of the gully. They were then accommodated tire to absorb the impact of the water passing through the palisade. The use of tires prevents water make a drag (hole) after the stockade, compromising its structure, as shown in Figure 7.

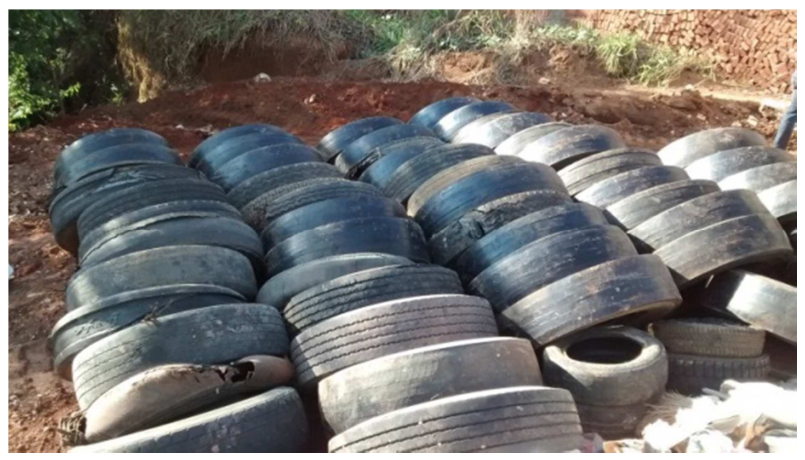

Figure 7. Tire use.

\subsubsection{Reconformation Ravines and Slopes}

The area voçorocamento presents part with ravines and unstable slopes, conducting reshaping is necessary to ensure stability and allow the planting and establishment of vegetation. This work was carried out with the use of machines in the dry season in order to have the area ready to accommodate planting at the beginning of the rainy season, as shown in Figure 8.

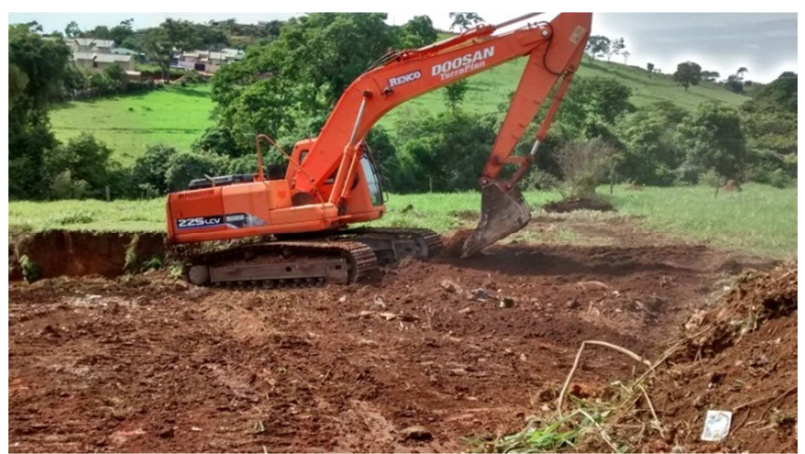

Figure 8. Use of machines for conformation.

\subsubsection{Initial Coverage Area}

After performing the mechanical practices, construction of palisades and the reshaping of slopes and ravines, passed to the application of plant remains for the formation of mulch on the eroded surface until the herbaceous, shrub and tree implanted to establish and ensure good protection to the soil. For this, we used the residue of vegetable origin such as straw, bark, sawdust, wood and other materials available in town, as shown in Figure 9.

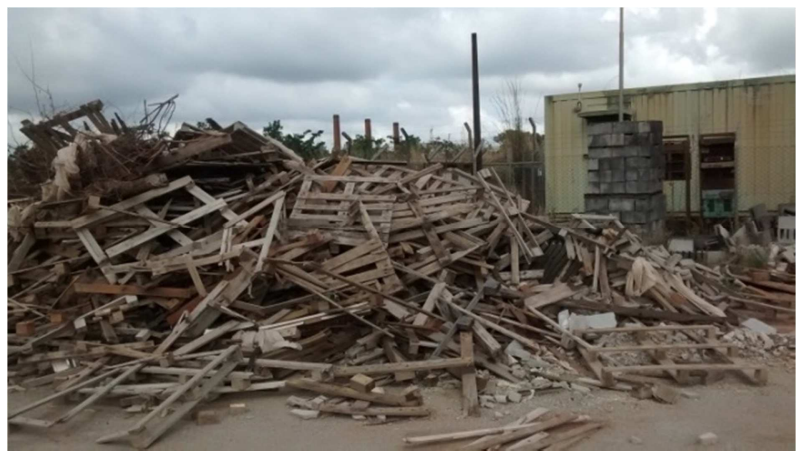

Figure 9. Used woods.

\subsubsection{Application of Biodegradable Products}

It was directly applied to the right surface completely biodegradable product (Embiotic - Throttle composting) to speed up the composting of organic materials that contribute to the recovery of the biota in the soil, control erosion and stabilization of slopes and embankments, Figure 10 shows the result during rain after application of this product.

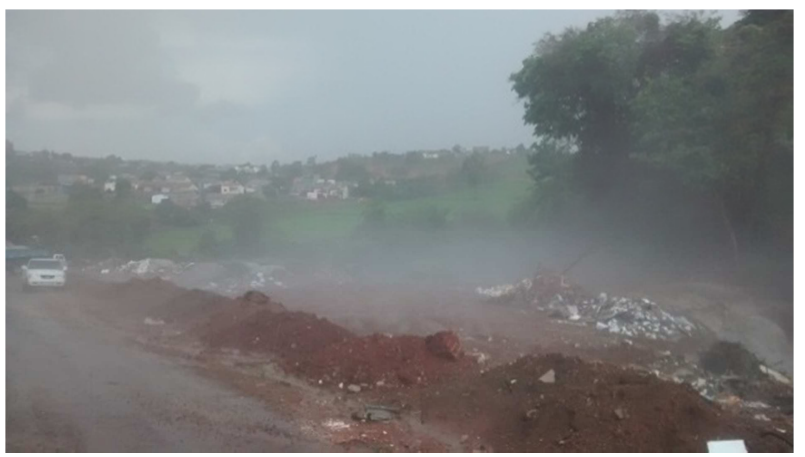

Figure 10. Result of the composting of organic matter.

\subsubsection{Revegetation of the Area}

For restoration of vegetation were used native species adapted to the region, such as legumes, rapid development of grasses and planted fruit still aiming to attract small animals. Deploying the process and accepting the assumption that all species regenerate naturally, it is expected that the same occurs with the production of seeds (flowering, pollination and maturation) and their consequent dispersion by the wind, birds, rodents, etc. ants in degraded points the old aggressive action.

The beginning of the planting process coincided with the beginning of the rainy season (fall / November). For the implementation of the measures in question, we used a least possible preparation of the soil, so as not to interfere with the physical structure of the same, because of the shallow. Thus, soil preparation occurred with small machines for plowing service and soil disking and planting species, forming a containment range in level, and also used the green mass of the corporation legumes, promoting Nitrogen fixation in the 
soil, improving soil fertility, increasing microbial activity and minimizing erosion. It was also used revegetation technology of slopes using material from other sites (organic fertilizer + soil + seed) packed in jute bags, set in inclined slope (of exposed Profile ravine) with wooden stakes.

The management made in floristic reconstruction of the area was performed using the intercalated planting of native species in Table 1.

Table 1. List, spacing, timing and method of planting species.

\begin{tabular}{|c|c|c|c|c|}
\hline Legumes / Native & Time & plantation & Spacing & Planting method \\
\hline $\begin{array}{l}\text { Crotalaria juncea } \\
\text { leucena } \\
\text { Leucenaleucocephaka } \\
\text { Calopogonio } \\
\text { Callopogomim } \\
\text { Muconoides } \\
\text { Guandu } \\
\text { Cajanus cajan } \\
\text { Dolichos lab lab } \\
\text { Mucuna black } \\
\text { Stizolobium atenium }\end{array}$ & October & January & $1,0 \mathrm{~m} \times 1,0 \mathrm{~m}$ & $\begin{array}{l}\text { The haul (taking care to make the coating of } \\
\text { seeds with little overburden) }\end{array}$ \\
\hline $\begin{array}{l}\text { Embaúba, yellow Ipe, Tabebuia sp, Garapa, } \\
\text { leiocarpa Apuleia, Angico, Gameleira, Ficus SP, } \\
\text { purple Ipe, Tabeuia SP, Inga, Inga SP, Jatoba. }\end{array}$ & November & January & $3,0 \mathrm{~m} \times 2,0 \mathrm{~m}$ & $\begin{array}{l}\text { Opening holes }(40 \mathrm{~cm} \times 40 \mathrm{~cm}), \text { mix the soil } \\
\text { removed from the hole with tanned manure at } \\
\text { the rate of }+100 \mathrm{~g} \text { of limestone. }\end{array}$ \\
\hline
\end{tabular}

In the range of 53 meters from the shore Street 04 into the attacked area was maintained at still existing vegetation and was not done cleaning so that not only create a protective strip, but the total coverage area, following the principle of the pioneer species will offer shading and fitting climax for the development of secondary that will arise during the process of natural revegetation.

After executing the planting, the site was irrigated with water until the 3rd (third) month to effective rooting (plant catches) and later made replanting in the event of death of some species. After 45 (forty five) days after the planting was held on topdressing with 100g of NPK 10-10-10 fertilizer per hole and cultural practices (weeding) around the graves. Combating the presence of ants and termites was necessary so that not having the inhibition of catches of the species. To this end, we used ant poison baits. The species were chosen taking into consideration the ease of obtaining seedlings and adaptation to the site to be vegetated.

Periodic inspections were carried out the excavation, erosion containment terraces and picks up the seedlings that were inserted into the area of interest. And carried out periodic maintenance on replanting to prevent the loss of grass layer formed on the surface thus accelerating the retreat of the attacked area. In Figure 11 is shown downstream of the gully recovered and restored vegetation.

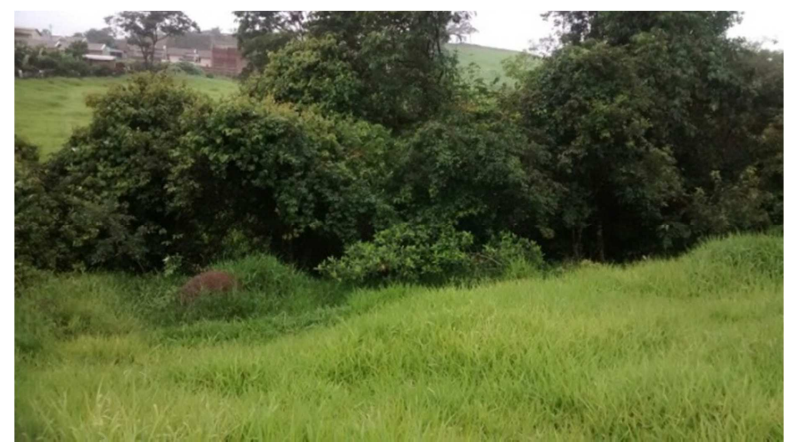

Figure 11. Downstream of the recovered gully.
Figure 12 provides a front view of the gully recovered and restored vegetation cover (quarantine area).

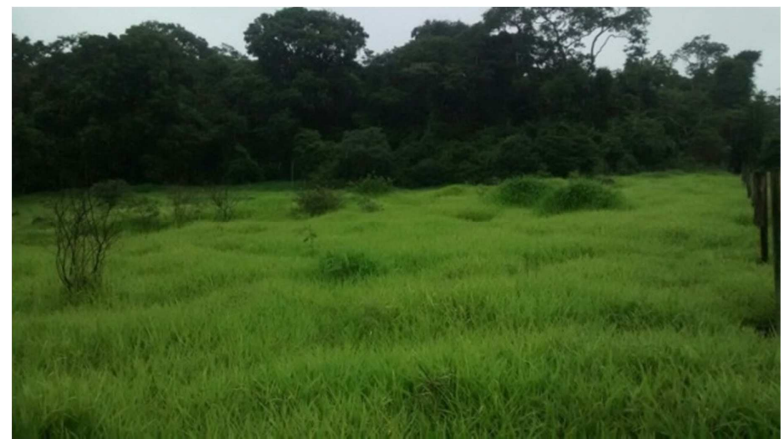

Figure 12. Front view of the recovered gully.

\subsection{Field Research}

The results of the field research were analyzed and represented in tables.

Observing Table 2, we realize that, in relation to the frequency of the means of transport that arrived at the scene to deposit the spoils, it was found that the most frequent day is Tuesday followed by the second and Thursday, after Wed fair and, finally, to Friday.

Table 2. Frequency of transport means a day.

\begin{tabular}{ll}
\hline Days of the week & Frequency \\
\hline Monday & 39 \\
Tuesday & 43 \\
Wednesday & 24 \\
Thursday & 39 \\
Friday & 18 \\
Total & 163 \\
\hline
\end{tabular}

The responsible authorities have taken the initiative to surround the whole area and prohibit your household waste disposal on site, making it clear, using cards that could only be deposited there rubble (construction and demolition 
debris), twigs and leaves, with accompanying supervisor of works and services of city hall.

Thus, it was found that only been deposited on-site materials listed in Table 3.

Table 3. Frequent Debris erosion.

\begin{tabular}{lll}
\hline Rubble Types & Frequency & Frequency $\%$ \\
\hline Construction & 68 & 43 \\
Organic (branches and leaves) & 64 & 41 \\
Mixed & 25 & 16 \\
Total & 157 & 100 \\
\hline
\end{tabular}

In the case of the types of means of transport responsible for the unloading of these materials, it was noticed that was common the presence of tractors, disk-dump trucks, carts, private cars and wheelbarrows.

The most frequent means of transport for the day were disk-dump trucks, followed by tractors, carts and finally other means of transport, as shown in Table 4.

Table 4. Types of discharges of transport.

\begin{tabular}{ll}
\hline Types of transport & Frequency \\
\hline Truck (disk-dump) & 91 \\
Tractor & 55 \\
Cart & 13 \\
Particular & 02 \\
Wheelbarrows & 07 \\
\hline
\end{tabular}

\subsection{Opinion Poll with Neighboring Residents}

An opinion poll in the homes of people with the association of neighborhood residents was held for approval by the recovery of the gully project (erosion) with segregated alternative materials (waste class IIB - inert according to NBR 10,004 - ABNT 2004a ) in the residential Geovanni Braga in Annapolis in the state of Goiás, as shown in Figure 13.

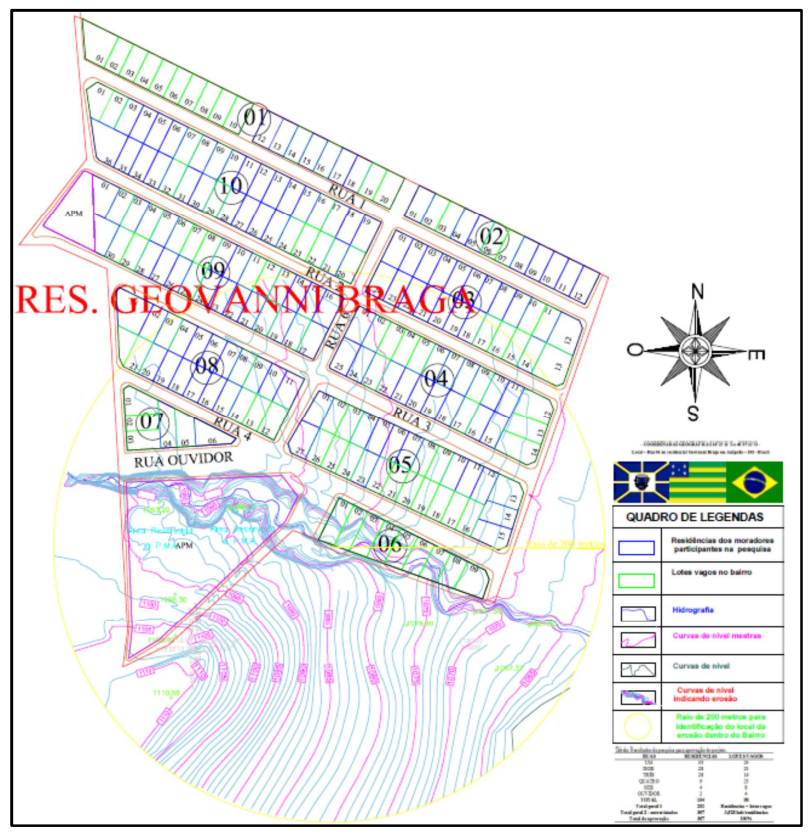

Figure 13. Survey map.
The survey was conducted on a total of 104 residences and 33 of One Street, Two 28 Street, 28 Street Three, 9 of Fourth Street, Sixth Street 4 and 2 of the Ombudsman Street. With a total of 367 residents interviewed, where he obtained 100\% approval with respect to the objective issue (approve or not approve).

Among the subjective responses of the respondents, the most indicative were chosen according to the objectives of this research, avoiding repetitions.

As to the question "What is your level of satisfaction (dissatisfied, satisfied or very satisfied) with regard to intervention in Residential Erosion Geovanni Braga? Why? "Were reported by respondents residents:

"We are very pleased because this erosion dating back to 1965 and never any government pledged to solve the problem."

"I am pleased because there was never any initiative on solving the problem. People threw garbage at this site, which caused various diseases in people in the region. "

"Yes I am very satisfied because they always played waste improperly on this site, and today over this bad habit."

As for the question "Do you believe that the work performed meets your expectations and wishes of the population? Why? "Were reported by respondents residents:

"Yes I believe. Why now this place will be able to build homes, and the neighborhood will become inhabited. "

"Yes, why the look of the region was something else, much better."

"Yes, why the improvements made were very good."

As for the question "Do you have perceived change in the quality of life for residents of this neighborhood? Why? "Were reported by respondents residents:

"Yes I have, people pass near the site where there was erosion without fear of being attacked by robbers who were hiding inside."

"Yes, I believe that improved in terms of safety and cleanliness."

"Yes, because there was too much waste deposited on this site, and today is a nice place to live."

As for the question "Do you believe are certain the actions taken to contain the erosion of Residential Geovanni Braga? Why? "Were reported by respondents residents:

"Yes I believe, why the professional who has developed and leads the project has assignments in two-class professional advice."

"I believe so, by involving the whole community in the neighborhood in order to solve the problem."

"Yes, the material used to contain the erosion complies with environmental standards."

The answers of respondents residents neighboring the recovered area, showed that they were satisfied with the intervention performed. No cases of dissatisfaction among respondents residents not being identified.

\section{Conclusion}

This research aimed to present the use of debris 
Construction in curbing the environmental impact of erosion Residential Geovanni Braga by the Municipal Works, Urban Services and Property Annapolis City Hall in the State of Goiás in the year 2015.

Based on the results obtained in this study it can be said that the use of the techniques employed proved to be surprising, presenting no erosive focus, and the visual impact of the site has been significantly improved. Since implementation costs were lower than traditional techniques.

It was concluded that the techniques used were adequate, efficient and mainly economic, to use reuse material donated by city collection companies.

The whole area was treated and covered with vegetation, which facilitated the infiltration of rainwater, being held in place only a small part that hit the lowlands and streams, thereby conserving soil moisture and improving the conditions of the same and adjacent.

The application of the composting accelerator immediately protected conserving soil moisture for a long period of time. Besides that after certain period it initiates composting providing nutrients to the soil which is absorbed by the root system of the plants and keeping the freshness of vegetables.

The mix of seeds and seedlings used was very important to have roots of species with different architecture and growth may keep the green all year round.

In synthesis techniques used in the treatment of erosion were rapid, highly efficient and greatly reduced cost compared to traditional methods. The results pleased the neighboring population improving the look, and not presenting that there was human interference there.

To continue this research is suggested to carry out similar studies in other regions with erosions.

\section{References}

[1] PEREIRA, A. New Technology in Erosion Control and Revegetation of Degraded Areas. I SYMPOSIUM BRAZILIAN IRON ORE, Ouro Preto, MG - Brazilian Association of Metallurgy and Materials, p 615-619, 1996.

[2] LOPES, S. L; WAR, A. J. T. Gullies Monitoring by GPS satellites in quartz sand areas podzolizada: Praia Mole, Florianópolis-SC. In. VII National Symposium on Erosion Control, Goiânia-GO, V. 1, No. 1, p. 106, 2001.

[3] GAlETI, P. A. Practice control erosion. Campinas: Campineiro Institute of Agricultural Education, 278 p., 1984

[4] PEREIRA, A. R. Bioengineering techniques used in soil protection and recovery. WORKSHOP ON ADVANCED TECHNIQUES IN Erosion control. PROCEEDINGS. SME Mining Society of Engineers, 1-8 p., 1997

[5] FERREIRA, R. R. M.; FERREIRA, V. M.; TAVARES FILHO, J.; RALISCH, R. Origin and evolution of gullies in Cambissolos in the basin of the upper Rio Grande, Brazil. In: XXXI Brazilian Congress of Soil Science, 2007, Gramado-RS. Proceedings, 2007.

[6] AB'SABER, A. N. Boçorocas of France. Journal of the School of Philosophy, Sciences and Letters of France, 1 (2): 5-27, France, in 1968.

[7] LIMA, M. C. Physical and chemical degradation and mineralogical massive along the gullies. Doctoral Thesis in Geotechnical Engineering, Department of Civil and Environmental Engineering, FT, UnB, Brasília, DF, 2003.

[8] IWASA, O.Y. \& FENDRICH, R. Urban Erosion Control. Oliveira, A. M. S., Brito, S. N. A. (Eds.). Engineering geology. Brazilian Association of Engineering Geology - ABGE, São Paulo, SP, p. 271-282, 1998.

[9] CAMAPUM DE CARVALHO, J.; SALES, M. M.; MORTARI, D.; FAZIO, J. A.; MOTTA, N. O. \& FRANCISCO, R. A. Erosive processes. Camapum de Carvalho, J. et al. (Org.). Erosion in the Midwest Brazilian, Finatec, Brasília, DF, 2006.

[10] MORGAN, P. R. C. Establishment of plant cover and parameters for modeling splash detachment. In: EL-SWAIFY, W. C.; MOLDENHAUER, W. C.; LO, A. (Eds.). Soil erosion and conservation. Ankeny, Iowa: Soil Conservation Society of America, p. 377-383, 1985.

[11] EMBRAPA SOIL. Technical report and monitoring plan of Degraded Areas Recovery Project. Rio de Janeiro, in 2002.

[12] CARVALHO, E. T. Project Manuelzão: river basin management course. Committees watershed of Arrudas and $\mathrm{Oz}$. Belo Horizonte, in 2004.

[13] CAPPI, M. D. Environmental restoration of eroded areas as the destination alternate ending of scrap tires. 60 2004. f. Thesis (MS) - Luiz de Queiroz College of Agriculture, University of São Paulo, Piracicaba, 2004.

[14] MARTINS, H. A. F. A. Use of Tire Rubber in Asphalt Pavement. Work Completion of course Universidade Anhembi Morumbi under the Civil Engineering Course with environmental emphasis. São Paulo, 2004.

[15] RAMOS. L. S. N. Reverse logistics scrap tires: The problem of location of collection points. Masters dissertation. Federal University of Santa Catarina, Program Graduate and Production Engineering, Florianópolis, 2005.

[16] HAUG, R. T.; The Practical Handbook of Engineering composting. Boca Raton, Lewis Publisher, Boca Raton, FL, 1993.

[17] IGNATIUS, C. T.; MILLER, P. R. M.; Composting: science and practice applied to waste management. EMBRAPA. 2009.

[18] GRAY, D. H. E. SOTIR, R. B. Biothechnical bioengineering slope and soil stabilization: A Practical guide for erosion control, John Wiley \& Sons, Inc., 1996.

[19] GOLDMAN, S. J. Erosion and Sediment Control Handbook, New York. McGraw-Hill, USA. 1986.

[20] GIL, A. C. Methods and techniques of social research. São Paulo: Atlas, 1999.

[21] GIL, A. C. How to develop research projects. 4. ed. São Paulo: Atlas, 2002.

[22] MATTAR, F. N. Marketing Research: Methodology and Planning. São Paulo: Atlas, 1996.

[23] YIN, R. K. Case Study: Planning and methods. Porto Alegre: Bookman, 2005. 
[24] NIMER, E. Climate. In: Climatology in Brazil. Rio de Janeiro: IBGE, 1989.

[25] JESUS, A. S. Multidisciplinary research of linear erosion: a case study of the city of Anapolis - GO. Doctoral Thesis, Publication G.T.D. 087/2013, postgraduate program in Geotechnical Engineering, Department of Civil Engineering University of Brasilia, 2013. 